\title{
Design and Innovation of Experimental Teaching for Software Engineering
}

\author{
Deng Tian \\ NanChang Institute of Science \& Technology
}

\begin{abstract}
Teaching of software engineering is faced with higher demands of quality proposed by the development of computer science as well as objective problems brought by massive higher education. The courses of software engineering should cultivate students into applied talents on software engineering. The courses of software engineering should carry out education according to students' characteristic and improve students' understanding and enthusiasm about theoretical knowledge by strengthening experimental practice. Thus, it is of vital importance to design and innovate experimental teaching. By analyzing the status quo and cultivation objects of computer teaching, experimental teaching contents for software engineering course have been delicately designed. We hope the concept and theoretical knowledge of software engineering can integrated into practice through a series of tools and experimental exercises so that students can have deep understanding about software engineering.
\end{abstract}

Keywords- Software engineering; Practice; Design; Innovation

\section{INTRODUCTION}

In 2006, Teaching Guidance Commission of computer science and technology in colleges and universities organized and formulated Standards for Majors of Computer Science and Technology in Colleges and Universities, Especially for Majors of Software Engineering under the leadership of Ministry of Education, within which it prescribes that professional educational contents and knowledge system should be set up during software engineering teaching in order to promote the teaching level of software engineering majors, cultivate talents on software engineering suitable for social development, and further promote the deep reformation and practice of curriculum teaching of software engineering with vigorous support of curriculum construction. Meanwhile, practical and feasible teaching plans should be proposed to form corresponding teaching resources. Network teaching system of software engineering exists in the teaching research and practice of software engineering courses in the form of digital teaching resources as an advantaged supplement, which will certainly produce deep influence on the reformation and practice of curriculum teaching on software engineering majors.

In the paper, it aims to form a complete, scientific and effective network teaching system of engineering software by combining network digital resources with traditional software engineering teaching. Detailed elaboration has been given to the development technologies and the whole design process of network teaching system of software engineering. The final purpose is to apply network teaching system of software engineering to practical teaching so as to improve the teaching level and promote the reform and practice of curriculum teaching of software engineering majors.

\section{THE SIGNIFICANCE OF DEVELOPING NETWORK}

TEACHING SYSTEM FOR SOFTWARE ENGINEERING

With the development of science and technology, people's ways and means to receive knowledge and study technologies have been changed a lot compared to last century, during which traditional teaching modes have also been greatly challenged. The traditional teachings modes cost much with poor property for update as well as less independence for study. Thus, study in this way can't be better extended to life deeply to cover groups of different levels.

Since there is an increasingly higher demand for the reform of teaching modes with wider coverage of computer network, network teaching is emerging at this historic moment. Network digital teaching resources have received sound teaching effect for its vivid and intuitive characteristics with wide coverage and less limitations to time and space. As a preferential supplement of traditional teaching methods, it has received more and more attention and importance.

At present, network education is mainly realized by remote teaching. Supported by computer network and satellite communication technologies, modern remote education has combined computer technologies, multi-media technologies, network and communication technologies with modern educational technologies. Compared to traditional teaching methods, it has quite a lot advantages and characteristics. For example, the main part of study has turned to students themselves without being restricted to time and space for the teaching activities; while they can determine the time, place, content and progress according to their own conditions. To sum up, network teaching has more flexible time and space with richer resources, more open system and more convenient coordination. However, with the deep development of modern remote education, its disadvantages and deficiencies have also become obvious, and its main setback is lack of timely interaction and communication with high demand on students' abilities such as self-consciousness and initiative of study. Thus, more consideration should be given to learners so as to reach better and maximum 
effect. Excellent network teaching materials suitable for network information expression and transmission such as images, words and voices should be employed with the support of teaching environment suitable for various teaching activities and management. Therefore, network teaching system suitable for students' independent study combined with teaching materials, question bank and practice all together has emerged, which has gradually supplemented the disadvantages of remote education. WebPages have been used to display questions, practice and teaching materials for network teaching.

\section{CIRCUMSTANCE FOR THE SYSTEM DEVELOPMENT}

The network teaching system of software engineering expresses the whole structure of teaching system in the form of browser or server by relying on the business website of Biological Identification and Information Safety Research Office in the Computer
Institute of Jilin University. The structure is shown in Fig .1 as follows. The website construction is carried out in the PHP operation environment deployed by UNIX server; while UNIX server possesses high safety and stability which can support large document system and database system with high practicability. As for the question bank of software engineering network teaching, it is mainly a $\mathrm{C} / \mathrm{S}$ self-testing system formed by $\mathrm{B}$ development tool and SQL server database.

Teaching materials of software engineering network system: teaching plate and Q\&A plate;

Question bank plat of software engineering network teaching system: self-testing system.

Practice plat of software engineering network teaching system: homework submission plate and document download plate.

The overall layout of the system is shown in the Fig .1 as follows.

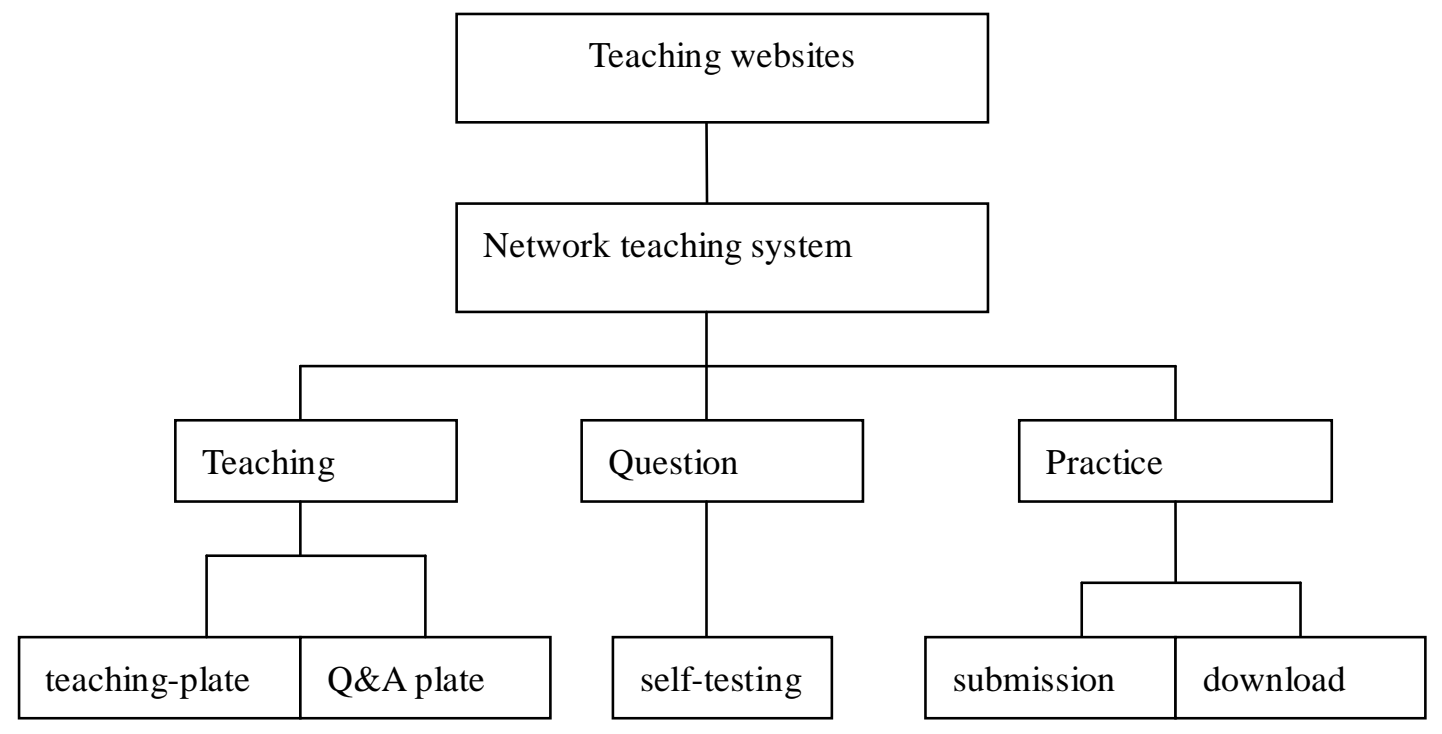

Figure 1. The overall layout of the system

\section{QUESTION BANK}

The question bank of software engineering network teaching system is self-testing system, and its main functions are as follows.

(1) The basic information management includes management on system administrator's logging information as well as input, modification and deletion of students' information;

(2) Management on test papers includes customized papers as well as selection of test titles and so on.
( 3 ) Management on question bank refers to management of judgment questions, selection questions, program reading questions and program fill-in questions and so on.

( 4 ) Management on examinations includes management on students' examinations, papers evaluation and result query.

The whole structure of self-testing system is shown in Fig .2 as follows. 


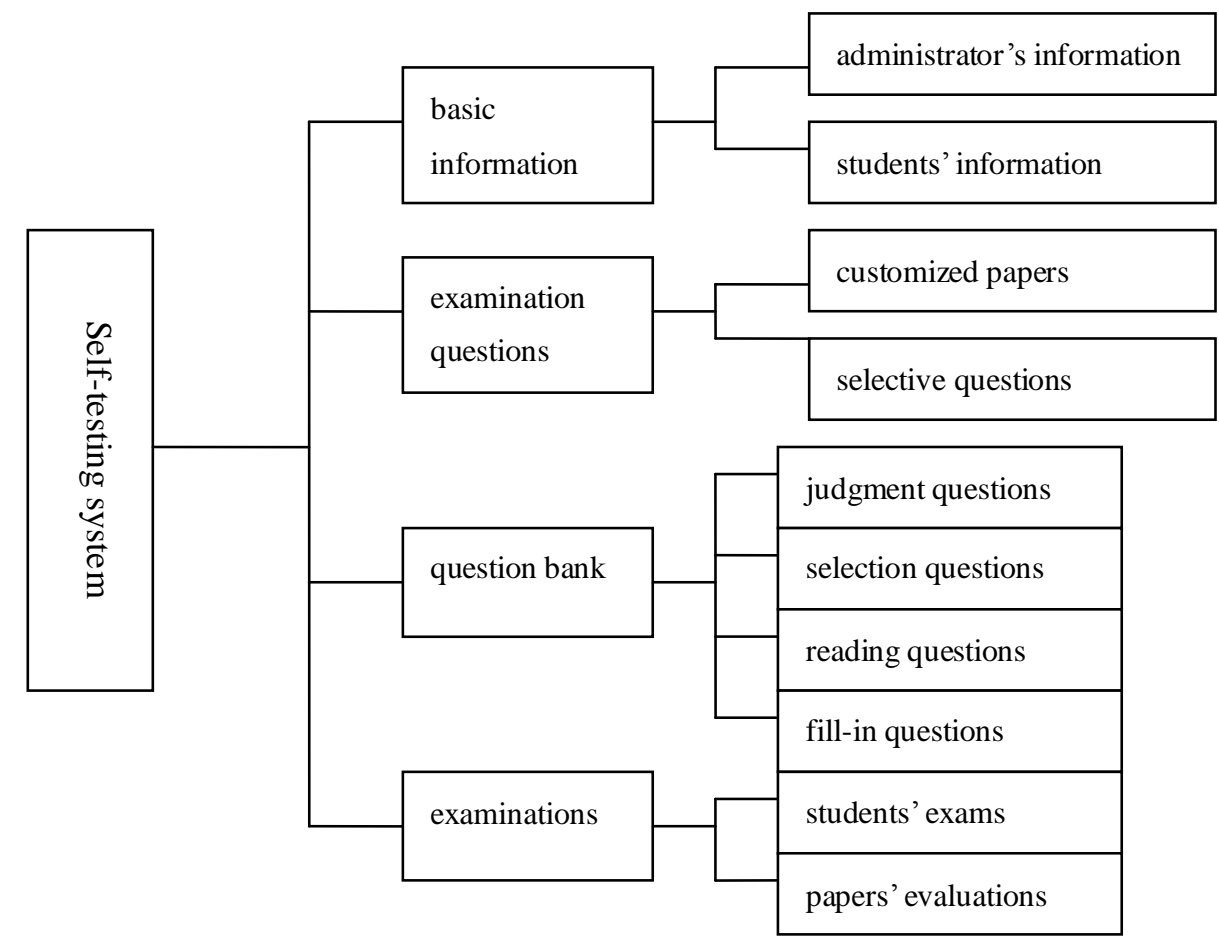

Figure 2. Self-test system structure

\section{V.PRACTICE}

The practice of software engineering network teaching system has designed detailed engineering projects for students, which requires students to gradually finish the design and submit project document in the network teaching system. This part includes mission arrangement plate, homework submission plate and document download plate, which can be seen in
Fig .3. The mission arrangement includes arrangement of project requirements and responsibilities; The homework submission plate includes documents of demand analysis, source code of system design, testing plan and report as well as download and upload of work conclusions, during which there are downloads of various tables and tools, etc.

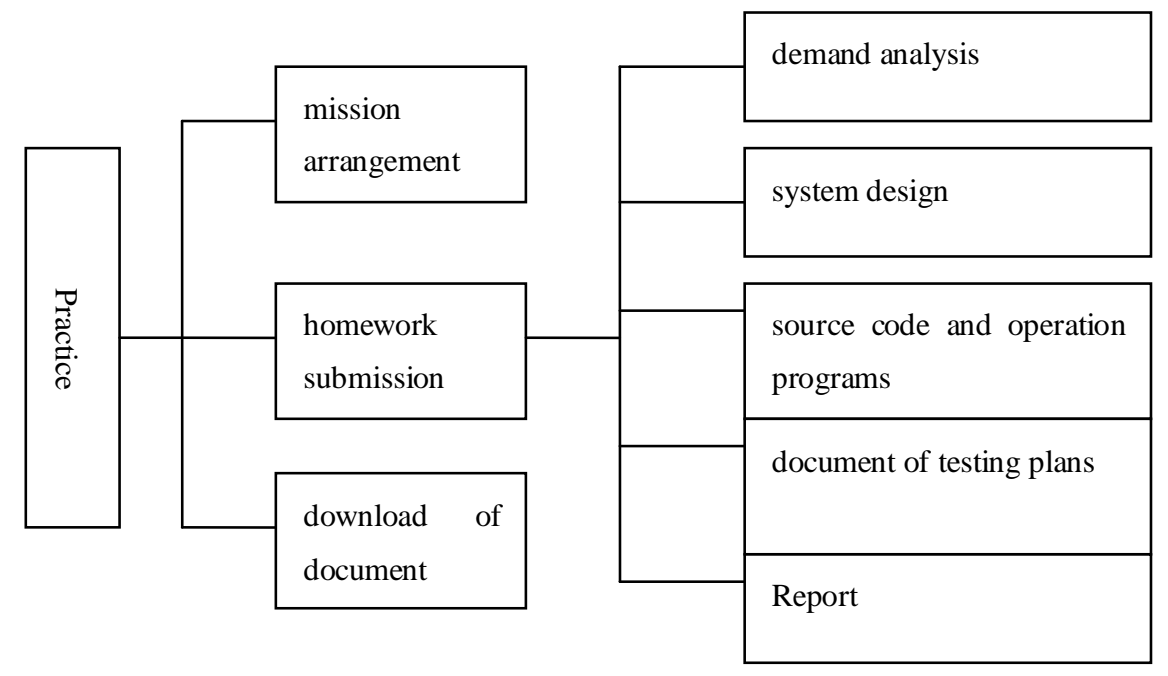

Figure 3. The flow chart of practice part

\section{CONCLUSION}

In the 21 st century, the relationship between science and technology and people's life has become increasingly closer. The progress of science and technology has not only greatly changed people's life, but it also changed people's way of receiving education. Modern teaching has perfected combined with computer and multi-media technologies, which enriches the original teaching methods and makes it possible for establishing a virtual school online. With the constant development of Web technology and we applications, 
remote education and network teaching has become a new type of teaching model gradually for its convenience. Network teaching system is quite popular among young people due to its unique characteristic and sound effect. Thus, it is very necessary for software engineering majors to design a network teaching system for college students' daily study.

The main content of this paper is to combine network digital technologies with traditional software engineering teaching so as to form a complete, scientific and effective network teaching system for software engineering.

\section{REFERENCE}

[1] Da-Jiang H. Research on Practice of Bilingual Teaching for Software Engineering $[\mathrm{J}]$. Journal of Hanshan Normal University, 2007.

[2] Da-Jiang, Honfg. "Research on Practice of Bilingual Teaching for Software Engineering." Journal of Hanshan Normal University (2007).

[3] Da-Jiang, H. (2007). Research on practice of bilingual teaching for software engineering. Journal of Hanshan Normal University.
[4] Dimarco S I. Soffware Strategist[J]. Registered Rep, 2011.

[5] Dimarco, Stephan Ie. "Soffware Strategist." Registered Rep (2011).

[6] You A. Application of Mine Foundation Class Library to the Development of Object-Oriented Soffware[J]. Journal Os Southern Institute of Metallurgy, 1999.

[7] Davis A M, Davis A M. Fifteen Principles of Software Engineering[J]. IEEE Software, 1994, 11(6):271 - 274.

[8] Umweltbundesamtes « B D. Stoffmono graphie Pentachlor phenol-Referenz- und Human-Biomonitoring-Werte (HBM) [J] Bundes gesundheitsblatt, 1997, 40(6):212-222.

[9] Groenink A. Surface without structures[J]. Word Order \& Tractability Issues, 1997.

[10] Alves C, Finkelsteiin A. Challenges in COTS decision-making: a goal-driven requirements engineering perspective[J]. Workshop on Software Engineering Decision Support in Conjunction with Seke', 2002, (2002):789--794.

[11] Abdi B, Safaei A, Moghani J S, et al. An Overview to Soft-Switching Boost Converters for Photovoltaic[J]. International Journal of Computer \& Electrical Engineering, 2013, 5(1)

[12] Viega J, Evans D. Separation of Concerns for Security[J]. Icse Workshop on Multidimensional Separation of Concerns in Software Engineering, 2000:126--129. 